\title{
THE THREE C's CONSERVE CONSUME AND CARE OF WATER FROM DAILY HOUSEHOLD CHORES: A STEP TOWARDS SUSTAINABLE FUTURE
}

\author{
Somya Tiwari ${ }^{1}$ Kanav Bhalla ${ }^{2}$ and Ayush Rawat ${ }^{3}$ \\ E-Mail ID: somyatiwari@ansaluniversity.edu.in \\ School of Engineering \& Technology, Ansal University, Gurgaon, Haryana, India
}

Abstract: Water is one of the main sources of life after air. Industrial development and modernization is happening so rapidly but without water life cannot be imagined. Water is consumed by all of us in different ways in daily life. As earth is covered with $70 \%$ of water but still water has globally become a matter of concern. In this paper small steps are discussed to save water. Even the industry that provides us with goods requires a lot of water for production. Some major problems are discussed in the paper which led to scarcity of water. Rapid growing population, that has led to more construction of houses that require a large amount of water. As to deal with all these problems we as engineers have come up with some inexpensive and easy ways to save water from being wasted and making it available and useful for some other purposes. Due to the advancement of technology and science it has been made possible to help take control of such problems very easily. Mentioned below are some ways to save water without investing a lot of money. Making proper pipe connections without leaks can save a lot of water. Not letting the water storage tanks overflow with the help of automated devices. Efficient use of water can be done by wise consumption, conservation and care of water so that future generation can also be benefited.

Keywords: Water Conservation, Consume, Care of Water, Daily Household Chores, automated devices.

\section{INTRODUCTION}

Today almost every person is familiar with the importance and necessity of water in our daily routines. Water is the most essential component for life on earth. All living beings need water to survive. There is a lot of water beneath the ground and large amounts of water are stored in the ground and this groundwater mainly comes from rainfall that penetrates downward from the land surface and the upper layer of the soil is the water. The surface where groundwater is present is called the water table. Below is the diagram of the water table shown in fig. 1.1.

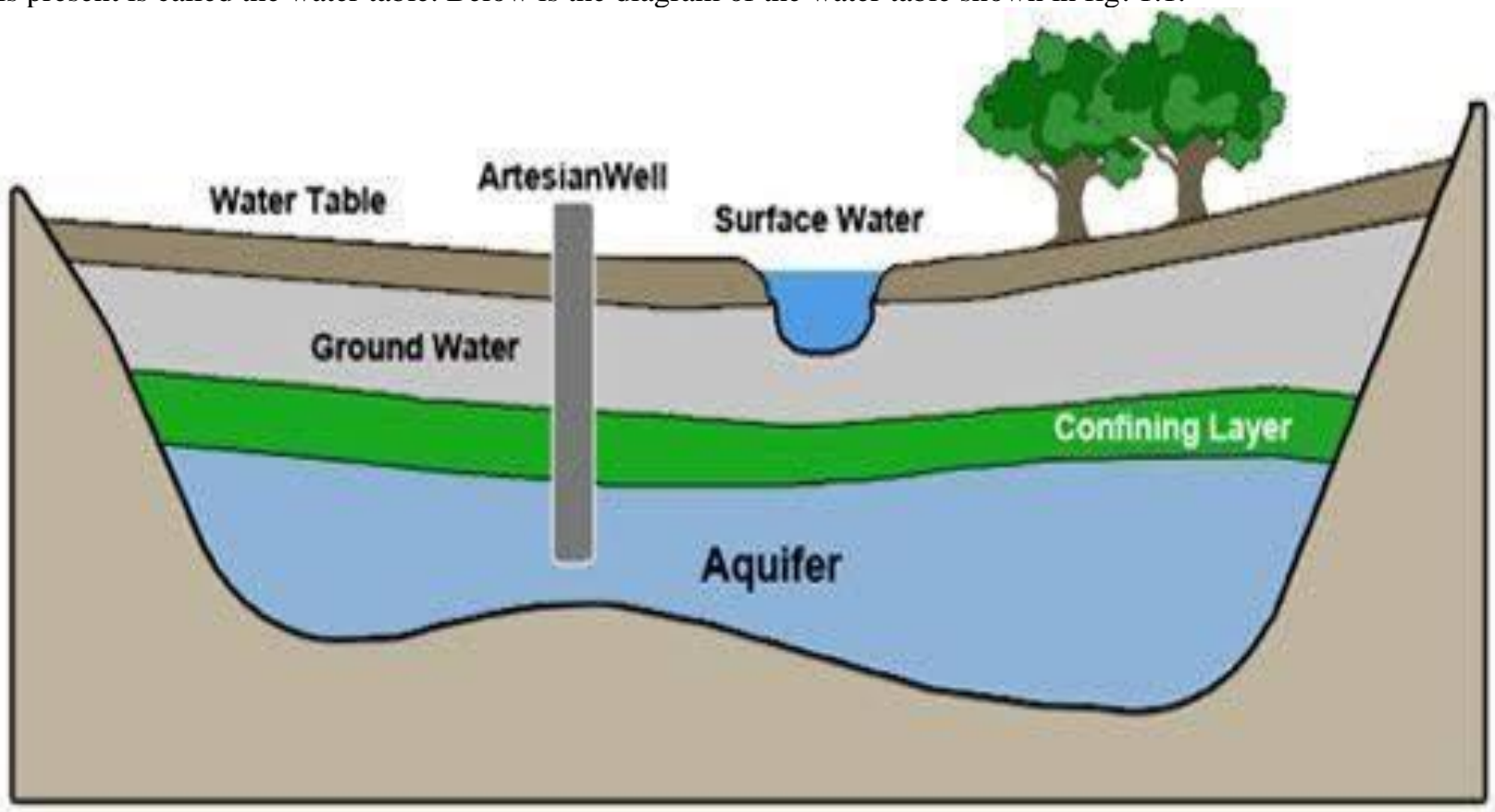

Fig. 1.1 Water table Diagram [10]

For freshwater, people have to drill holes deep down to have access to clean groundwater. An aquifer is an underground layer in which the soil and rock is present with water below the ground. The water levels change with due course in time due to global warming that changes the weather and rain cycle patterns causing permanent environmental damages.

The pumping of groundwater artificially can have a drastic impact on water levels below in fig. 1.2. 
ICACCG2020 30-31 July, 2020, Ansal University, Gurgaon, India

International Journal of Technical Research \& Science (Special Issue)

ISSN No.:2454-2024 (online)

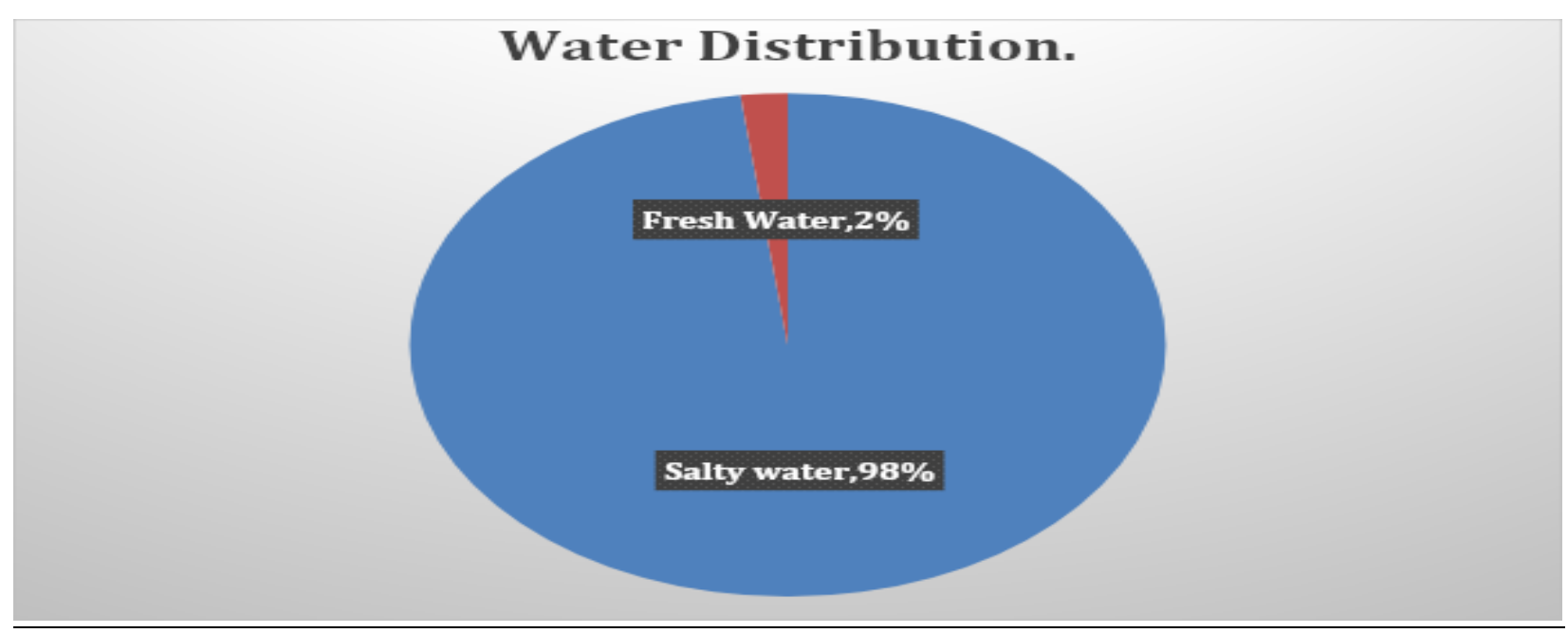

Fig. 1.2 World Water Distribution

This chart shows that about 97 percent of the earth's water is salty water and the remaining 3 percent is freshwater. Further fresh water is divided into ice i.e. 86 percent of freshwater, groundwater i.e. 11 percent of freshwater and then is remaining 2 percent of rivers and lakes. [5]. A layer of transition is seen under the ground that separates salty water and freshwater beneath. Till now we have seen how much water is present in the world and the effects of various types of water extraction ways. Now there is a brief discussion about how we are wasting water in our day to day life so that we as an individual work on it to reduce the wastage of this precious water. According to the rough estimation an average person wastes up to 114 litres of water every day. In this world where the majority of the population lacks access to fresh water and sanitation, it's shameful that we waste so much water, especially in densely populated cities. One of the main reasons for wastage of water is when we use our toilets as a trash can. Every time you flush, you waste six to eight litres of water. Now the other big reason for wastage of water is by taking bath multiple times in a day or by taking long relaxing showers. The average Indian shower uses up to sixteen to twenty-five litres of water and lasts up to 8 minutes and that's a lot of water wastage.

Another big reason are the conventional showerheads. For less water wastage, always switch to a low-flow showerhead which saves up to seven to nine litres of water. Another reason is because of leaky pipes. According to an Indian News report, it says that an average household can leak more than 35 to 40 litres of water per year.

Laundry loads that are only half full are also the most common and big reason for wastage of clean water. To save water and energy which will save us money to we should only run the washing machine when the load is full. Running a dishwasher that's not completely full wastes a lot of clean water. Overwatering your lawn is one of the reasons for wasting water. During the summer season, it's best to water your lawn and plants in the morning between 5-10am because the air is cool. Now the most common mistake you all do is to keep the tap open while brushing your teeth. If you keep the water running when you're brushing your teeth or shaving a lot of clean water is wasted, place a notice near your washbasin that reminds you to save water while brushing or shaving. As a result, in order to control the water depletion and promote water conservation and rainwater harvesting, our government has enforced certain actions towards the issue. The National Water Policy has been sentenced by the Department of Water Resources and Government relations advocates rain water harvesting and conservation of water and highlights the need for increasing the availability of water through direct use of rainfall. Along with it importance of conservation of river, river bodies and infrastructure should be undertaken in a planned manner through involvement of people [8]. Moreover, the government has passed various guidelines to states to enlighten them the optimum utilization of monsoon rainwater and to work out on groundwater collection as a first step towards development which includes rain water harvesting. So far, about 15 States have worked and are using the groundwater collection guidelines. Also the Central Ground Water Authority(CGWA) is giving 'No Objection Certificate (NOC)' for drawing ground water for mandatory rainwater harvesting. Various programmes for mass awareness are conducted to promote rainwater harvesting and recharging ground water by artificial means. The Government of India has also approved many schemes for the management of ground water harvesting with the involvement of state people where scarcity of water is present like Gujarat, Haryana and Rajasthan.

\section{SAVE WATER AND IT WILL SAVE YOU (WATER SAVING TECHNIQUES)}

\subsection{Low-Flow Faucets and Showerheads}

One of the most effective ways to save water is by replacing our showerheads and faucets with low-flow restrictors [3]. Low-flow showerheads and fittings are a little bit expensive but can help to save a lot of water. Many studies have shown that by switching all your fittings to low-flow faucets per household can reduce its water wastage by $30-60 \%$ and helps to save money on water bills. Low-flow restrictors are provided with smart home technology sensors to bring down your water wastage. [1]

DOI Number: https://doi.org/10.30780/specialissue-ICACCG2020/013

pg. 38

Paper Id: IJTRS-ICACCG2020-013

@ 2017, IJTRS All Right Reserved, www.ijtrs.com 


\subsection{Leak Detectors}

Leaks in water pipes are one of the major issues when it comes to wastage of clean water. Smart homes enabled leak detectors to monitor moisture around pipes and walls [4]. When you connect your mobile phone with these devices, they send notifications whenever they detect condensation, drips or leaks around the pipes or walls.

\subsection{Irrigation Controls}

Smart AI enabled sprinkler systems can be scheduled according to the local weather forecast. Many people often over or under water their plants or fields, but smart AI enabled irrigation systems ensures that the garden is not overwatered or under watered hence saving the plants and water. These irrigation systems keep a check on weather forecasts so that accordingly it will supply the water. The system can also be controlled from your smartphones. By using this system, you can save up to $50 \%$ of your water usage for gardening.

\subsection{Energy Star Appliances}

Energy star appliances can save a lot of energy and significantly save our money. Many old appliances like washing machines and dishwashers use up to 75 litres of water per cycle and in the same cases if we use an energy star washer then it uses 40 litres of water per cycle which makes a huge difference. [2]

\subsection{Shower Timers}

Showering is a necessary part of life and one should always keep a track on water consumption. There are many devices that can solve the issue of over usage of water during showers by fixing a timer for your shower routines. The device can be placed next to your shower and keeps a record of the amount of water being used for every shower [2]. Accordingly, the device will try to accommodate to reduce your shower time. The indicator will be green when you start, light will turn yellow when you're in the middle of your shower, and then the light will turn red when the showering time is over. With this device we can save a lot of water and money.

\subsection{Rainwater Harvesting}

We can also save a lot of water by collecting it and storing your own water during the rains. An underground tank collects rainwater that can then be used for irrigation purposes. Rainwater harvesting can approximately save up to 2000 litres of rainwater. The simplest way to set up a rainwater harvesting system is by connecting a water storage tank to the drain pipe of the top most roof. Furthermore, it can be filtered and used for general purposes. [3]

\subsection{Water Overflow Sensor}

One main reason for water wastage is overflowing water tanks. To solve this problem, we can use this Sonoff sensor which may directly report to the government about the overflowing water tanks. The sensor can work with SONOFF RF Bridge 433, alarm system, etc. When it detects water overflowing the alarm notification message will be immediately sent to the APP on the phone. It Can be equipped with a wireless fidelity host. It's a DIY product and installing it is very easy. When the two probes of the sensor are immersed in water, it will give a flash and send an alarm message to the controlling app on the phone. Ideal water saving device for homes, apartments (kitchen, toilet), warehouses, offices. To solve the overflow problem of the tanks this device can also be installed for homes, hospitals, industries, etc. and saves water, electricity and time. It consists of three sensors, one sensor is placed at the bottom, second sensor is placed in the middle, and the third sensor is placed at the top of the tank. When the water level in the tank goes down by the middle sensor the motor automatically starts filling the tank till the water level reaches the top sensor. This device is very useful and can save a lot of water.

\subsection{Smart Water Valve Controller}

One main cause of water wastage is forgotten open taps. This device is the perfect solution to the problem. As we all have WIFI at home, this device can be connected through the WIFI and be controlled via app from any part of the world. It can be fitted to the main supply pipe coming from the overhead tank and hence the flow can be controlled via a click of a button. It fits all kinds of 3/4" models of water pipeline valves. It can be controlled and monitored by a mobile phone not only helps in saving water but also helps in preventing leakages and the best part is this device can be controlled remotely.

\subsection{RO waste water $=$ washing machine water}

Many households nowadays use washing machines to do their laundry. While using waste water from RO water purifiers as shown in the picture above, it saves a lot of time and effort and a lot of water. Transferring large quantities of water to the washing machines can be strenuous. A storage tank of the waste water from RO water purifier that is fixed right over a washing machine. Instead of draining away, the water poured directly into the machine and can be used for washing clothes. Waste RO water can also be used for washing utensils, cars and for other purposes.

\subsection{Automatic Sensor IR Device for Sink Faucet}

According to various sources washing hands can waste up to 10 litres of water. We can save that water by using this IR based water dispenser. This device can be installed on a faucet and can control the flow of water. This is a sensor 
ICACCG2020 30-31 July, 2020, Ansal University, Gurgaon, India

International Journal of Technical Research \& Science (Special Issue)

ISSN No.:2454-2024 (online)

based device which only allows water to flow when it detects some motion. Presently there are sensor based water taps in the market, but this budget friendly device can be installed on preinstalled taps you do not need to buy new water taps.

\section{CONCLUSIONS}

Water concerns are not situated in one side of the country. It is an important element for survival on which life depends on. The level of drinking water under the ground is becoming less because of the disturbance in groundwater table. Also deforestation causes rainwater to run away instead of going inside the ground. Summarizing to all the points mentioned above if followed properly will save a lot of water, money as well as the environment.

\section{REFERENCES}

[1] https://www.homeselfe.com/save-water-using-smart-home-technology/ (18/02/20).

[2] https://www.electronichouse.com/home-energy-management/8-high-tech-ways-to-save-water (20/02/20).

[3] https://lentheplumber.com/blog/top-10-ways-youre-wasting-water/ (18/02/20).

[4] https://www.volusia.org/services/growth-and-resource-management/environmental-management/naturalresources/water-conservation/25-ways-to-save-water.stml\# (02/03/20).

[5] https://www.usgs.gov/special-topic/water-science-school/science/groundwater-storage-and-water-cycle?qtscience_center_objects=0\#qt-science_center_objects (02/03/20).

[6] http://cgwb.gov.in/CGWA/NGT/JodhpurCityRising_WL_Final_Report.pdf (18/02/20)/.

[7] http://mowr.gov.in/sites/default/files/Steps_to_control_water_depletion_Jun2019.pdf (20/02/20).

[8] https://www.hindustantimes.com/delhi/have-an-overflowing-tank-get-ready-to-pay-up-rs-2-000-fine/storyUVLAD4OmHdfOGleUTxINUP.html (20/02/20).

[9] https://www.health24.com/Lifestyle/Environmental-health/see-how-much-water-do-you-use-per-day- 0170613 $(20 / 02 / 20)$.

[10] https://encryptedtbn0.gstatic.com/images?q=tbn\%3AANd9GcQQvtF5Ehc4FC22YpkdkzRlcNtjSE_sQz67ikUX3Zaat8eLcOUC (18/02/20).

[11] https://www.epa.gov/sites/production/files/2017-03/documents/ws-factsheet-outdoor-water-use-in-the-us.pdf $(24 / 04 / 20)$.

[12] http://www.icao.int/publications/Documents/9952en.pdf (24/04/20).

[13] http://www.sydneyairport.com.au/corporate/about-us/building-a-better-airport/waterrecycling-plant.aspx $(13 / 04 / 20)$.

[14] https://link.springer.com/article/10.1007/s12273-017-0387https://www.sciencedirect.com/science/article/abs/pii/S0959652611003064

[15] www.elsevier.com/locate/jenvman.

[16] Silva, C.M.; Sousa, V. Carvalho, N.V., Evaluation of rainwater harvesting in Portugal. 2015. 